\title{
Sacrococcygeal Teratoma: Experience with 36 Patients in a Teritiary Care Hospital
}

\author{
Kundal VK ${ }^{1}$, Jadhav $A^{2}$, Gupta $A^{3}$, Shukla $A K^{4}$, Chaturvedi $V^{5}$, Kundal $R^{6}$
}

\begin{abstract}
Introduction: Sacrococcygeal teratomas (SCT) are the most common solid tumours in the neonatal period, originate from embryonic totipotent cells. Most of them are benign however some that present later in life and have major intra-pelvic component have greater malignant potential. Complete surgical excision provides an excellent prognosis. The aim of this study was to describe the clinical profile, age of presentation, sex distribution, diagnostic evaluation and management of children with a histological confirmed diagnosis of sacrococcygeal teratoma. Material and Methods: Patients with histological diagnosis of sacrococcygeal teratoma during a period from January 2011 to December 2012 were included in this retrospective study. Data collected included age of presentation, sex distribution, symptoms, associated anomalies, diagnostic evaluation, operative approach technique employed, tumour histology, operative complications and outcome. Results: Thirty six patients with diagnosis of sacrococcygeal teratoma were included in the study. Of these children, $58.33 \%$ were females and $41.66 \%$ were males. The median age at presentation was four days. $69.44 \%$ of patients presented during the neonatal period. $77.77 \%$ of patients presented with sacrococcygeal mass followed by lower abdominal mass in $11.11 \%$. The tumour was resected by sacral approach in 27 patients and abdomino sacral approach in nine patients. Tumour was resectable in 34 patients and two had incomplete resection. Follow up duration varied from six months to 24 months. Conclusion: Sacrococcygeal teratomas represent a group of benign and malignant lesions of children. Neonates present with benign disease and aggressive lesions are seen as age progresses. Overall survival of SCT is high.
\end{abstract}

Key words: Sacrococcygeal teratoma, totipotent cells, immature teratoma, Alfa-fetoprotein, Cisplatin based chemotherapy

\section{Introduction}

Cacrococcygeal teratomas (SCT) are the most common solid $S$ tumours in the neonatal period with a reported incidence of $1: 35,000$ to $1: 40,000$ live births ${ }^{1,2}$. These tumours arise from the Henson's node, believed to originate from embryonic totipotent primitive cells ${ }^{3}$. It is more common in females with male: female ratio of $1: 3-4^{4}$. These tumours are composed of two or three germ
'Dr Vijay Kumar Kundal, Assistant Professor, Department of Paediatric Surgery, PGIMER and Dr Ram Manohar Lohia Hospital, New Delhi, ${ }^{2}$ Dr. Avinash Jadhav, Assistant Professor, Department of Paediatric Surgery, PGIMER and Dr Ram Manohar Lohia Hospital, New Delhi, ${ }^{3}$ Dr. Arun Gupta, Professor, Department of Paediatric Surgery, Sawai Man Singh Medical College and Hospital, Jaipur, Rajasthan, ${ }^{4}$ Dr. Arvind Kumar Shukla, Professor, Department of Paediatric Surgery, Sawai Man Singh Medical College and Hospital, Jaipur, Rajasthan, ${ }^{5}$ Dr. Vinita Chaturvedi, Professor, Department of Paediatric Surgery, Sawai Man Singh Medical College and Hospital, Jaipur, Rajasthan, ${ }^{6}$ Dr. Raksha Kundal, Consultant, Department of Anaesthesia, BL Kapoor Memorial Hospital, New Delhi, India.

Address for correspondence:

Dr. Vijay K Kundal

E-mail:vijayraksha@yahoo.com

\section{How to cite}

Kundal VK, Jadhav A, Gupta A, Shukla AK, Chaturvedi V, Kundal R. Sacrococcygeal Teratoma: Experience with 36 Patients in a Teritiary Care Hospital. J Nepal Paediatr Soc 2015;35(1):89-93.

doi: http://dx.doi.org/10.3126/jnps.v35i1.10945

This work is licensed under a Creative Commons Attribution 3.0 License.

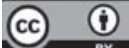

cell layers and can present in varying sizes and shapes ${ }^{5}$. Most germ cell tumours in neonates are benign and are divided into mature and immature teratomas ${ }^{6}$. However, fewer tumours that present later in life and have major intra-pelvic component have greater malignant potential. Complete surgical excision of these tumours provides an excellent prognosis ${ }^{7}$. 
The aim of this study was to study the clinical profile, age of presentation, sex distribution, diagnostic evaluation and management of children admitted in our hospital with a histological confirmed diagnosis of sacrococcygeal teratoma.

\section{Material and Methods}

A total of 36 patients were received during the period from January 2011 to December 2012 in the Department of paediatric surgery, Sawai Man Singh medical college and hospital, Jaipur, India. The medical records of the patients regarding age of presentation, sex distribution, presenting symptoms, associated anomalies, various blood and radiological investigations done, type of operative approach and tumour histopathology and complications associated with operative were reviewed retrospectively. Only histopathological confirmed cases of sacrococcygeal teratomas were included in the study. Lumbosacral meningomyelocoeles who were initially misdiagnosed as teratomas were not included in the study.

\section{Results}

Thirty six patients with histopathological diagnosis of sacrococcygeal teratoma were included in the retrospective study. The study included 21 (58.33\%) females and 15 (41.66\%) males. The median age at presentation was 4 days, with ranges between day one to five years. $25(69.44 \%)$ patients presented during the neonatal period and 9 (25\%) patients presented during the period of one year excluding neonatal period. Only two (5\%) patients presented after the period of one year (Table 1). Out of 36 patients, 19 patients had undergone antenatal ultrasonography and only six patients were diagnosed with large sacrococcygeal mass. Clinical presentations of all 36 patients included in the study are described (Table 2).

Table 1: Showing age of presentation of sacrococcygeal teratomas

\begin{tabular}{|c|c|}
\hline Age of Presentation & $\begin{array}{c}\text { No of Patients } \\
\text { (Percentage) }\end{array}$ \\
\hline Neonates(less than 1 month) & $25(69.44 \%)$ \\
\hline Infants(>28 days- 1 year) & $9(25 \%)$ \\
\hline$>1$ year & $2(5 \%)$ \\
\hline
\end{tabular}

Most of the patients presented with sacrococcygeal mass $(77.77 \%)$ followed by lower abdominal mass (11.11\%), urinary tract and gastrointestinal tract obstruction. Only three patients presented with associated anomalies. One patient had polydactyly, other had anorectal malformation \& clubfoot and the $3^{\text {rd }}$ one had occipital encephalocoele. All patients were investigated by baseline blood investigations, X-ray and Ultrasonography abdomen and pelvis, Serum Alfa-feto protein (AFP) contrast enhanced computed tomography (CECT) abdomen and pelvis preoperatively. Serum Alfa-fetoprotein is normally elevated in the first eight months, therefore such high levels should be interpreted with caution in infants. Beyond this age, serum Alfa feto-protein has significant oncologic relevance. Serum Alfa-feto protein was raised in four patients of 11, 12, 18, 24 months age group. These levels normalized six to nine months after surgery.

Table 2: Showing clinical manifestations

\begin{tabular}{|l|c|}
\hline \multicolumn{1}{|c|}{ Presentation } & $\begin{array}{c}\text { No. of Patients } \\
\text { (Percentage) }\end{array}$ \\
\hline Antenatal diagnosis & $6(16.66 \%)$ \\
\hline Sacrococcygeal mass & $28(77.77 \%)$ \\
\hline Lower abdominal mass & $4(11.11 \%)$ \\
\hline Urinary tract obstruction & $3(8.3 \%)$ \\
\hline Gastrointestinal obstruction & $2(5.5 \%)$ \\
\hline $\begin{array}{l}\text { Associated anorectal } \\
\text { malformations }\end{array}$ & $1(2.7 \%)$ \\
\hline
\end{tabular}

Altman's classification in 36 patients was type $I(n=15)$, type $I I(n=12)$, type $I I(n=5)$ and type IV( $n=4)$. The tumour was resected by sacral approach in 27 patients and abdomino-sacral approach was employed in nine patients. The tumour was resectable in 34 patients and had two patients had incomplete resection, biopsy followed by chemotherapy. Standard cisplatin based chemotherapy was given in our patients. Coccygectomy was done in all patients. The mass was purely cystic in 11 patients and having heterogenous consistency in 18 patients and only seven patients had pure solid component. Gonzalez-Crussi grading of teratoma in our 36 patients is as, grade $0(n=27)$, grade I $(n=4)$, grade II $(n=3)$ and grade III $(n=2)$.

Table 3: Altman classification of Sacrococcygeal teratoma in 36 patients

\begin{tabular}{|c|c|}
\hline Type & $\begin{array}{c}\text { No. of Patients } \\
\text { (Percentage) }\end{array}$ \\
\hline Type I & $15(41.66 \%)$ \\
\hline Type II & $12(33.33 \%)$ \\
\hline Type III & $5(13.88 \%)$ \\
\hline Type IV & $4(11.11 \%)$ \\
\hline
\end{tabular}

In a follow up duration, that varied from 6 month to 24 months, two patients had recurrence who were managed by re-do surgery and chemotherapy. Two patients of grade 3 immature teratoma were also placed on cisplatin-based chemotherapy. Peri- 
operative complications occurred in seven patients that included surgical site infection in two patients, one of which required sigmoid colostomy and other was managed with regular dressings and prone position. Massive Intraoperative bleeding occurred in one patient, managed by ligation of sacral vessels and blood transfusion. Recurrence was seen in two patients (Gonzalez-Crussi grade 3) and managed by re-excision and chemotherapy. One patient presented with postoperative faecal soiling which improved over a period of 3 month follow up. One patient died of septicaemia on $10^{\text {th }}$ post-operative day.

Table 4: Gonzalez-Crussi histopathologic grading

\begin{tabular}{|c|c|}
\hline $\begin{array}{c}\text { Grade (percentage of immature } \\
\text { tissue) }\end{array}$ & $\begin{array}{c}\text { No. of Patients } \\
\text { (Percentage) }\end{array}$ \\
\hline Grade 0 (no immature tissue) & $27(75 \%)$ \\
\hline Grade I (< 10\% immature tissue) & $5(13.88 \%)$ \\
\hline $\begin{array}{c}\text { Grade II (10\%-50\% immature } \\
\text { tissue) }\end{array}$ & $2(5.5 \%)$ \\
\hline Grade III (>50\% immature tissue) & $2(5.5 \%)$ \\
\hline
\end{tabular}

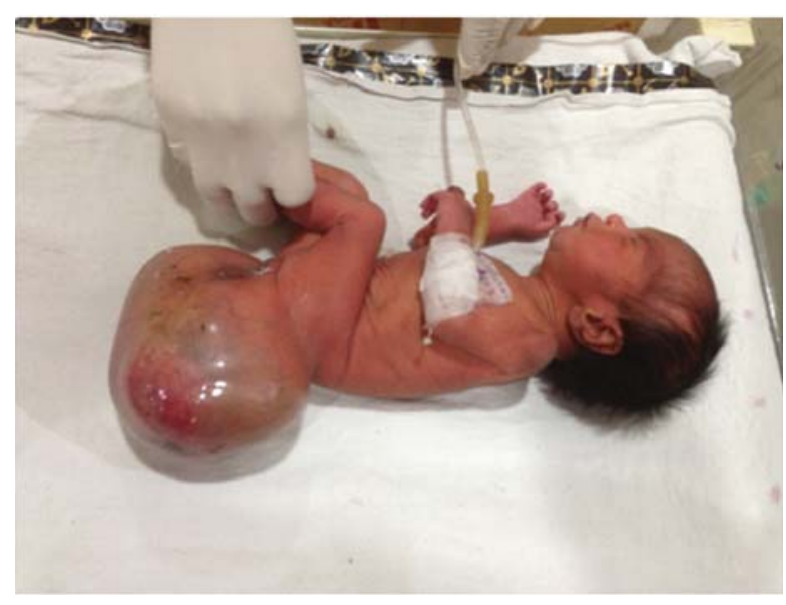

Fig 1: showing large sacrococcygeal mass in a neonate

\section{Discussion}

Sacrococcygeal teratomas (SCT) are well known germ cell tumours affecting neonates, infants and children. These tumours have bimodal age of distribution; those presenting in the neonatal period predominantly having benign course and older infants and children with intrapelvic tumour having malignant histology ${ }^{8}$. The disease is predominantly more common in females worldwide, but in our series, there is only slight increased female preponderance. In Wakhlu et al study from India shows equal sex distribution ${ }^{4,9}$. The incidence of SCT is 1:35,000-40,000 live births ${ }^{2}$. In our series, 36 patients were seen over a period of two years. The incidence is much more as compared to the 33 patients and 38 patients in 25 years Canadian and 18 years Nigerian study respectively ${ }^{10,11}$. In recent years, antenatal detection of the Sacrococcygeal mass has increased manifold in western world due to better imaging modalities and with tertiary care services at doorsteps, antenatal detection has enabled better outcome. But in developing countries, poverty, poor perinatal care, low education justify the delayed timing of presentation of disease. Antenatal ultrasonography (USG) has increased the detection of disease and has enabled possible antenatal intervention and planned caesarean deliveries resulting in better outcome. More than half of our patients presented during neonatal period. In our series of 36 patients, 11 patients had antenatal USG done and only five patients could be detected as having sacrococcygeal mass. 19 patients had undergone antenatal ultrasonography and only six patients were diagnosed with large sacrococcygeal mass. $69.44 \%$ of our patients presented during neonatal period, probably because of external lesions and rest presented later. Timing of presentation also relates to the low socio-economic status and scarcity of tertiary care institutions in developing countries like India.

As per Rescorla et al, all patients presenting after the age of one year had malignant tumours ${ }^{12}$. Gabra et al also reported that $71 \%$ of their patients presenting beyond neonatal period were malignant ${ }^{13}$. These interpretations are consistent with our results, two patients who presented beyond 1 year of age had $>50 \%$ immature tissue (malignant component) on histology. Altman classification divides SCT according to its anatomical location and intrapelvic extension ${ }^{1}$. As per published reports, Altman type I,II,III,IV is seen in $47 \%, 35 \%, 8 \%$ and $10 \%$ cases respectively. In our series of 36 patients, incidence of four types was $41.66 \%$, $33.33 \%, 13.88 \%$ and $11.11 \%$ respectively, which is comparable to the American Academy of Pediatrics data. Commonest mode of presentation is sacral mass followed by pelvic tumour. Other less common modes of presentations are bowel obstruction, urinary obstruction, and ulceration over the swelling. Ascraft and Holder in 1965 reported the association of sacral mass with sacral defect and anal stenosis ${ }^{14,15}$. Association of SCT along with anorectal malformation and sacral agenesis is called as Currarino triad ${ }^{16}$. In our study, one patient had Currarino triad with bladder and bowel symptoms.

The diagnostic evaluation of SCT involves, blood investigations, USG abdomen, pelvis and sacral region. Serum alfa-fetoprotein is an important tumour marker used to monitor recurrence of disease and malignant 
change. Although computed tomography and Magnetic resonance imaging are considered better imaging modalities, as they give better tumour characterization and its relationship to adjacent structures. Current management strategy in the western world is antenatal diagnosis with a planned caesarean delivery and immediate excision of the tumour ${ }^{17,18}$.

The treatment of SCT involves complete surgical excision with coccygectomy as in our cases. In case of benign lesions, excision is sufficient. Failure to remove the coccyx results in recurrence as high as $37 \%{ }^{19,20}$. In malignant lesions (immature components), cisplatinum-based chemotherapy and radiotherapy is indicated ${ }^{21}$. Surgical approach depends upon the size and anatomical location of the tumour. Altman type I and II can be removed by sacral route and type III and IV lesions can be approached by combined abdominosacral route. In our series type I,II and even some cases of type III were approached by sacral route and type IV were operated by combined abdomino-sacral approach.

Postoperative complications after SCT excision include surgical site infections (SSI), haemorrhage, rectal dysfunction, urinary incontinence. SSIs are considered to be due to proximity to anal opening and continuous faecal soiling of wound. Ein SH et al reports an infection rate of $18 \%$ in surgical wound ${ }^{10}$. In another study by Wakhlu et al surgical site infection was seen in only two patients. ${ }^{9}$ Our series also reported SSI in two patients, haemorrhage in one patient, recurrence in two patients (grade 3), faecal soiling in one patient which improved with follow up and one patient expired of septicaemia. We feel that long term follow up is required to deal with bowel and urinary symptoms and delayed complications.

Teratomas are graded according to the GonzalezCrussi classification on the basis of percentage of immature and neuroepithelial element ${ }^{22}$. It includes grade I, II, III having, <10\%, 10\%-50\%, >50\% immature component respectively. Our results reveal $75 \%$ of patients had benign disease (no immature element) and only $5.5 \%$ patients revealed grade III disease.

\section{Conclusion}

We conclude that most cases of sacrococcygeal teratomas present in neonatal period as sacrococcygeal mass. Neonates present with benign disease and aggressive malignant lesions are seen in age group beyond the neonatal period and young children. Diagnostic evaluation includes clinical examination, USG and CT abdomen and pelvis and serum Alfa-fetoprotein levels. Complete removal of the tumour along with coccygectomy and avoidance of intra-operative spillage is associated with excellent prognosis. Late age of presentation and presence of immature components are associated with poor prognosis. Post operative complications after tumour excision are known. Compliance with follow up visits requires good parental counselling and super speciality services at the doorsteps.

Acknowledgements: $\mathrm{Nil}$

Funding: Nil

Conflict of Interest: None

Permission from IRB: Yes

\section{References}

1. Altman RP, Randolph JG, Lilly JR. Sacrococcygeal teratoma: American academy of paediatrics surgical section survey-1973. J Pediatr Surg 1974;9:389-98.

2. Tapper O, Lack EE. Teratomas in infancy and childhood. A 54 year experience at the children hospital medical centre. Ann Surg 1983;198:398410.

3. Tuladhar R, Patole SK, Whitehall JS. Sacrococcygeal teratoma in the perinatal period. Postgad Med J 2000;76:754-59.

4. Keslar PJ, Buck JL, Suarez ES. Germ cell tumors of the sacrococcygeal region: radiologic-pathologic correlations. Radiographics 1994;14:607-20.

5. Gatcombe HG, Assikis V, Kooby D, Johnstone PA. Primary retroperitoneal teratomas: a review of the literature. J Surg Oncol 2004;86:107-13.

6. Hart I Jr: Perinatal(fetal \& neonatal) germ cell tumors. J Pediatr Surg 2004;39(7):1003-13.

7. Exelby PR. Sacrococcygeal teratoma in children. $C A$ Cancer J Clin 1972;22:202-8.

8. Billmore DF, Grosfeld JL. Treatomas in childhood: Analysis of 142 cases. J Pediatr Surg 1986;21:548-51.

9. Wakhlu A, Misra S, Tandon RK, Wakhlu AK. Sacrococcygeal teratoma. Pediatr Surg Int 2002;18:384-87.

10. Ein SH, Adeyemi SD and Mancer K. Benign Sacrococcygeal teratomas in infants and children: A 25 year review. Ann Surg 1980;191:382-84.

11. Abubakar AM, Nggada HA, Chinda JY. Sacrococcygeal teratoma in Northeastern Nigeria: 18- years experience. Pediatr Surg Int 2005;21:64548. 
12. Rescorla FJ, Sawin RS, Coran AG, et al. Long term outcome for infants and children with sacrococcygeal teratoma: a report from the children cancer group. J Pediatr Surg 1998;33:17176.

13. Gabra HO, Jesudason EC, McDowell HP, et al. Sacrococcygeal teratoma- a 25 year experience in a UK regional center. J Pediatr Surg 2006;41:1513516.

14. Havranek $P$, Hedlund $H$, Reubenson A, Guth D, Husberg M, Frykberg $T$, et al. Sacrococcygeal teratoma in Sweden between 1978 and 1989: long term functional results. J Pediatr Surg 1992;27:916-18.

15. Malone PS, Spitz L, Kiely EM, Brereton RJ, Duffy PG, Ransley PG. The functional sequelae of sacrococcygeal teratoma. J Pediatr Surg 1990;25:679-80.

16. Currarino GCD, Votteler T. Triad of anorectal, sacral \& presacral anomalies. AJR Am J Roentgenol 1981;137:395.
17. Chuileannain FN, Woodrow N, de Crespigny L. Prenatal diagnosis and management of sacrococcygeal teratoma. Aust NZ J Obstet Gynaecol 1999;39:497-501.

18. Okada T, Sasaki F, Cho K, Honda S, Naito S, Hirokata G, Todo S. Management \& outcome in prenatally diagnosed sacrococcygeal teratoma. Pediatr Int 2008;50:576-80.

19. Jouannic JM, Dommergues M, Auber F, et al. Successful intra-uterine shunting of a sacrococcygeal teratoma(SCT) causing fetal bladder obstruction. Prenat Diagno 2001;21:82426.

20. Matiour HG, Woolley MM, Trivedi SN, et al. Sacrococcygeal teratoma: a 33- year experience. J Pediatr Surg 1975;10:183-88.

21. Match M, Arya NC. Sacrococcygeal teratoma: two case reports \& a review. Obstetr Gynaecol Commun 2000;2:34-6.

22. Gonazalez-Crussi, F. Extragonadal teratomas. Atlas of tumor pathology, second series, Fascicle 18, Washington D.C: Armed forces institute of pathology; 1982. 